\title{
Enhanced anti-tumor activity of a new curcumin-related compound against melanoma and neuroblastoma cells
}

\author{
Marina Pisano ${ }^{+1}$, Gabriella Pagnan+2, Maria Antonietta Dettori1, Sara Cossu¹, Irene Caffa², Ilaria Sassu', Laura Emionite³,

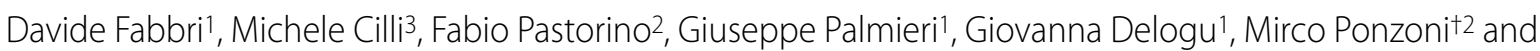 \\ Carla Rozzo*+1
}

\begin{abstract}
Background: Sharing the common neuroectodermal origin, melanoma and neuroblastoma are tumors widely diffused among adult and children, respectively. Clinical prognosis of aggressive neuroectodermal cancers remains dismal, therefore the search for novel therapies against such tumors is warranted. Curcumin is a phytochemical compound widely studied for its antioxidant, anti-inflammatory and anti-cancer properties. Recently, we have synthesized and tested in vitro various curcumin-related compounds in order to select new anti-tumor agents displaying stronger and selective growth inhibition activity on neuroectodermal tumors.
\end{abstract}

Results: In this work, we have demonstrated that the new a, $\beta$-unsaturated ketone D6 was more effective in inhibiting tumor cells growth when compared to curcumin. Normal fibroblasts proliferation was not affected by this treatment. Clonogenic assay showed a significant dose-dependent reduction in both melanoma and neuroblastoma colony formation only after D6 treatment. TUNEL assay, Annexin-V staining, caspases activation and PARP cleavage unveiled the ability of D6 to cause tumor cell death by triggering apoptosis, similarly to curcumin, but with a stronger and quicker extent. These apoptotic features appear to be associated with loss of mitochondrial membrane potential and cytochrome c release. In vivo anti-tumor activity of curcumin and D6 was surveyed using sub-cutaneous melanoma and orthotopic neuroblastoma xenograft models. D6 treated mice exhibited significantly reduced tumor growth compared to both control and curcumin treated ones (Melanoma: D6 vs control: $P<0.001$ and D6 vs curcumin $P<0.01$; Neuroblastoma: D6 vs both control and curcumin: $P<0.001$ ).

Conclusions: Our data indicate D6 as a good candidate to develop new therapies against neural crest-derived tumors.

\section{Background}

Malignant melanoma (MM) and neuroblastoma (NB) are different cancers which share a common neuroectodermal origin, besides being dissimilar for all other pathological aspects such as tissue involvement, metastasis development and age of onset.

MM, the most lethal skin cancer, preferentially develops metastases in lymph-nodes and visceral sites (mostly lung, liver and bone-marrow): it also presents a high frequency of skin metastases. Its incidence rates have

\footnotetext{
* Correspondence: carla.rozzo@icb.cnr.it

1 Istituto di Chimica Biomolecolare, CNR, Sassari, Italy

+ Contributed equally

Full list of author information is available at the end of the article
}

increased continuously during the last decades in fair skin populations of western countries [1]. When MM is diagnosed early it can be successfully removed by surgical resection, and about $80 \%$ of cases are dealt with in this way [2]. However metastatic MM has a very poor prognosis, with a median survival rate of 6 month and a 5-year survival rate of less than 5\% [3].

Neuroblastoma is the most common extracranial solid tumor of childhood, and accounts for one of every eight pediatric cancer deaths [4]. The tumor derives from the developing sympathetic nervous system and most primary tumors occur within the abdomen, with at least $50 \%$ arising from the adrenal glands [5]. The main feature of neuroblastoma is its remarkable biological heterogeneity, 
which becomes apparent in the broad variety of the clinical courses of the disease [6]. Besides, at least $40 \%$ of all children with neuroblastoma are designated as high-risk patients, meaning that this disease remains a major problem in pediatric oncology.

Both these tumors are refractory to conventional chemotherapy and/or radiation treatment actually in use, hence search for novel therapies is warranted and new therapeutic approaches are needed. Curcumin (diferuloylmethane) is the main product extracted from the rhizome of Curcuma Longa, a tropical plant native to South and Southeast Asia. It appears as a yellow powder and it is routinely used in the cuisine of the Indian subcontinent as a major component of curry spice. Described in the ancient test of Ayurveda and traditional Chinese medicine for thousands of years, curcumin has been used for the treatment of different inflammatory diseases [7]. As a medicine, curcumin exhibits remarkable anti-oxidant, anti-inflammatory and anti-cancer activities [8]. Chemopreventive and growth inhibitory activities of curcumin against many tumor cell lines, including drug-resistant ones, have been reported [9]. Taking into account the complexity and involvement of multiple signaling pathways in cancer growth and progression, a drug such as curcumin, which can interact with multiple target molecules, would be more efficacious than the current monotargeted anticancer drugs [10]. Indeed, curcumin targets several steps in the biochemical pathways leading to cancer (see [9] for a review). It suppresses the expression of cyclin D1, which is deregulated in several types of tumor, and it also induces apoptosis in tumor cells by activating caspase-8, which leads to cleavage of Bid, thus resulting in sequential release of mitochondrial cytochrome $c$ and activation of caspase- 9 and caspase-3, cleavage of poly ADP ribose polymerase (PARP) and apoptosis of tumor cells. Moreover curcumin suppresses the activation of several transcription factors that are implicated in carcinogenesis: it suppresses the activation of nuclear factor kappa B (NFkB), activator protein 1 (AP-1), and at least two of the signal transducer and activator of transcription proteins (STAT3, STAT5). Curcumin also modulates expression of genes involved in cell proliferation, cell invasion, metastasis, angiogenesis, and resistance to chemotherapy [11] and it shows a potent chemopreventive activity against a wide variety of tumors. Recently, curcumin has been reported to exert a good antiproliferative activity on melanoma cells by inducing apoptosis [12]. In several types of human melanoma cells, curcumin induces apoptosis through the Fas receptor/caspase- 8 pathway independent of p53 and suppresses the antiapoptotic gene XIAP [13]. Overall, several pilot clinical trials using curcumin against various tumors have been reported; however, its concentration levels in serum and tissues have been demonstrated to remain very low due to its poor bioavailability and high instability under physiological conditions [9].

A number of curcumin related compounds have been synthesized by our group and tested in vitro in order to select new antitumor agents displaying stronger and selective growth inhibition activity on melanoma cells (unpublished data). It has been previously reported that hydroxylated biphenyl structures could be effective as cytotoxic agents in MM and NB cells, with apoptotic inducing capability [14]. On this basis we evaluated the possibility to design a molecule that, while keeping or improving the biological properties of curcumin, could exploit the activity of hydroxylated biphenyl compounds, which are generally more bioavailable. In this paper, we describe the synthesis of the new curcumin-related biphenyl compound D6, an $\alpha, \beta$-unsaturated ketone, and test its anticancer properties. Antiproliferative and proapoptotic activity of D6 has been assessed by in vitro experimental procedures on MM and NB cell lines showing D6 more effective than curcumin in inhibiting tumor cells growth and inducing apoptosis by involving the intrinsic pathway. In vivo assays on both $\mathrm{MM}$ and $\mathrm{NB}$ mouse models have also been carried out, confirming the D6 anticancer potentiality.

\section{Methods \\ Chemicals}

Curcumin (D1, Figure 1) was purchased from Alfa Aesar (GmbH \& Co KG, Karlsruche, Germany), with a purity of $95 \%$, dissolved in dimethyl sulfoxide (DMSO) at a final concentration of $100 \mathrm{mM}$ and stored at $-20^{\circ} \mathrm{C}$ until used. For in vitro experiments, D1 was diluted in complete medium to contain $<0.1 \%$ DMSO, immediately before use. For in vivo experiments, D1 was diluted in a sterile $0.9 \%(\mathrm{w} / \mathrm{v}) \mathrm{NaCl}$ solution containing $1.65 \mathrm{mg} / \mathrm{ml}$ bovine serum albumin (BSA, Sigma, St. Louis, MO, USA) and $3.6 \%$ DMSO (v/v), as reported with slight modifications

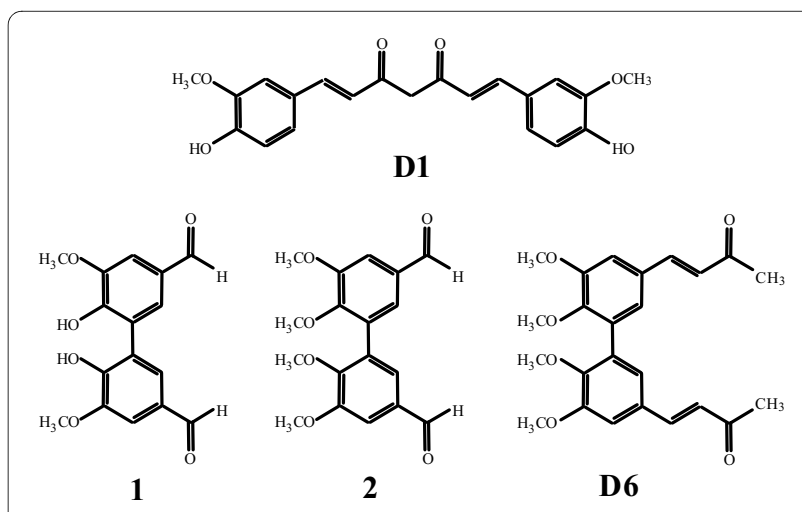

Figure 1 Chemical structures. Curcumin D1 and related biphenyl D6 with its precursors (1) and (2). 
$[15,16]$. D1 dilutions were freshly prepared immediately before injection and protected from light.

Pan-caspase inhibitor (z-VAD-FMK) was purchased from Sigma.

\section{Synthesis of D6}

The new curcumin-related biphenyl compound, the $\alpha, \beta$ unsaturated ketone D6 was synthesized as follow (Figure 1):

Preparation of 2,2',3,3'-tetramethoxy-5,5'-diformyl-1,1'biphenyl (2).

$\mathrm{CH}_{3} \mathrm{I}$ (1.41 g, $\left.9.93 \mathrm{mM}\right)$ was added, dropwise at RT under $\mathrm{N}_{2}$, to a solution of 2,2'-dimethoxy-3,3'-dihydroxy5,5'-diformyl-1,1'-biphenyl (1) [17] (1.0 g, $3.31 \mathrm{mM})$ and $\mathrm{K}_{2} \mathrm{CO}_{3}(1.37 \mathrm{~g}, 9.93 \mathrm{mM})$ in $20 \mathrm{ml}$ of dry acetone. The solution was stirred at reflux for 12 hours and washed with water $(100 \mathrm{ml})$. The organic phase was extracted with ether $(2 \times 100 \mathrm{ml})$ and dried over $\mathrm{Na}_{2} \mathrm{SO}_{4}$ to obtain a yellow solid. The crude material was purified by flash chromatography using a 6:4 mixture of petroleum:acetone as eluent to give (2) as a white solid. $(0.87 \mathrm{~g}, 80 \%)$ : mp $130-131^{\circ} \mathrm{C} ;{ }^{1} \mathrm{H}$ NMR $\delta 3.76$ (s, 6H), 3.97 (s, 6H), 7.38 $(\mathrm{d}, J=2.0 \mathrm{~Hz}, \mathrm{Ar}, 2 \mathrm{H}), 7.49$ (d, $J=2.0 \mathrm{~Hz}, \mathrm{Ar}, 2 \mathrm{H}), 9.90$ (s, $2 \mathrm{H}) ;{ }^{13} \mathrm{C} \mathrm{NMR} \delta 56.07,60.99,110.17,127.44,131.57$, 131.87, 152.11, 153.15, 190.69; Anal. Calcd for $\mathrm{C}_{18} \mathrm{H}_{18} \mathrm{O}_{6}$ : C, 65.45; H, 5.49; Found: C, 65.55; H, 5.38.

Preparation of $\left(3 E, 3^{\prime} E\right)-4,4^{\prime}-\left(5,5,6,6^{\prime}\right.$-tetramethoxy[1,1'-biphenyl]-3,3'-diyl)bis(but-3-en-2-one) (D6).

A $1 \mathrm{~N}$ solution of $\mathrm{NaOH}(1.6 \mathrm{ml})$ was added, dropwise, to a solution of 2,2'3,3'-tetramethoxy-5,5'-diformyl-1,1'biphenyl (2) (1.65 g, $0.5 \mathrm{mM})$ in dry acetone $(10 \mathrm{ml})$. The solution was stirred at RT for 12 hours. The solvent was evaporated. $10 \% \mathrm{HCl}$ was added $(100 \mathrm{ml})$, the organic phase was extracted with dichloromethane $(2 \times 100 \mathrm{ml})$ and dried over $\mathrm{Na}_{2} \mathrm{SO}_{4}$ to obtain a yellow solid. The crude material was purified by flash chromatography using a 6:4 mixture of petroleum: acetone as eluent to give (D6) as a white solid. (1.07 g, 52\%): $\mathrm{mp} 166-167^{\circ} \mathrm{C}$; ${ }^{1} \mathrm{H}$ NMR $\delta 2.35$ (s, 6H), $3.69(\mathrm{~s}, 6 \mathrm{H}), 3.95(\mathrm{~s}, 6 \mathrm{H}), 6.63(\mathrm{~d}, J=16.4 \mathrm{~Hz}, 2 \mathrm{H})$, $7.05(\mathrm{~d}, J=2.0 \mathrm{~Hz}, \mathrm{Ar}, 2 \mathrm{H}), 7.11(\mathrm{~d}, J=2.0 \mathrm{~Hz}, \mathrm{Ar}, 2 \mathrm{H})$, $7.45(\mathrm{~d}, J=16.4 \mathrm{~Hz}, 2 \mathrm{H}) ;{ }^{13} \mathrm{C}$ NMR $\delta 27.46,55.91,60.85$, $110.80,124.10,126.47,129.82,132.32,143.04,149.05$, 153.02, 198.22; Anal. Calcd for $\mathrm{C}_{24} \mathrm{H}_{26} \mathrm{O}_{6}$ : C, 70.23; $\mathrm{H}$, 6.38; Found: C, 69.89; H, 6.48.

\section{Cell lines and culture conditions}

Malignant melanoma (MM) cell lines [LB24Dagi (LB24), CN-MelA (CN), GR-Mel (GR), WM266-4 (WM), 13443, and M14] were a gift from Dr. D. Castiglia at Istituto Dermopatico dell'Immacolata, Department of Molecular and Cellular Biology, in Rome, as reported [14]. The following human neuroblastoma (NB) cell lines were used: GI-LIN, HTLA-230, SH-SY5Y, LAN5, SK-NBE2c, and IMR-32
$[18,19]$. Normal human fibroblasts BJ (CRL-2522) were purchased from the American Type Culture Collection (ATCC) and served as controls. All cells were grown either in Dulbecco's minimal essential medium (DMEM, Sigma) or in RPMI medium (Invitrogen, Carlsbad, CA, USA), as described $[14,18,19]$.

\section{Cell proliferation assay}

All MM (3-5 $\times 10^{3}$ per well $)$ and NB $\left(8-12 \times 10^{3}\right.$ per well $)$ cell lines were plated in 96-well plates in complete medium and treated in quadruplicate with different concentrations of either D1/D6 $(0-25 \mu \mathrm{M})$ or $0.1 \%$ DMSO (control) for 72 hours. The percentage of MM cell proliferation was estimated on day 5 by the colorimetric assay of Kueng et al. [20] modified as previously reported [21]. Neuroblastoma cells were incubated overnight with 0.5 $\mu \mathrm{Ci}(0.0185 \mathrm{MBq})^{3} \mathrm{H}$-thymidine (Amersham Bioscience, Little Chalfont, UK) and processed for liquid scintillation counting (Packard Instruments Company, Downers Grove, IL, USA), as described [19].

To assess the effect of duration of drug exposure on cell proliferation, we also performed drug washout experiments, according to the method described by Keshelava et al. [22]. Briefly, the D1/D6-containing medium was removed from the cultures after 6 or 12 hours by washing the cells twice with complete medium. The cells were subsequently covered with fresh drug-free complete medium and incubated for a total incubation time of 72 hours. Cell proliferation was evaluated by either measuring DNA synthesis as a function of ${ }^{3} \mathrm{H}$-thymidine uptake or by the colorimetric assay, as above $[19,21]$.

\section{Clonogenic cell survival assay}

MM (LB24) and NB (GI-LI-N) cells were suspended at concentrations of $3 \times 10^{5}$ cells $/ \mathrm{ml}$, treated with either D1 or D6 $(0,2.5,5,10$, or $20 \mu \mathrm{M})$ in culture medium for 4 hours and then plated (in triplicate) at 50 (LB24) and 300 (GI-LI-N) cells per well into 12-well plates with fresh drug-free medium. Cells were incubated for an additional 14 days, then the colonies in each well were stained, counted and photographed [18].

\section{Apoptosis assays}

\section{Terminal deoxynucleotidyl transferase-mediated dUTP nick} end labeling (TUNEL) assay

LB24 melanoma cells and BJ fibroblasts were plated in 8 well-chamber slides $\left(5 \times 10^{4}\right.$ and $5 \times 10^{5} /$ well, respectively), cultured for 24 hours, and then treated with either D1 or D6 $(10 \mu \mathrm{M})$. After further 24 hours, DNA cleavage was assessed by enzymatic end-labeling of DNA strand breaks using a commercial kit (In Situ Cell Death Detection Kit, Roche, Penzberg, Germany), according to the manufacturer's instructions and as previously reported [14]. 


\section{Phosphatidylserine detection}

For detection of phosphatidylserine exposure, cultured LB24 cells $\left(1 \times 10^{6} / 25 \mathrm{~cm}^{2}\right.$ plastic culture flask $)$ and GILI-N cells $\left(2 \times 10^{6} / 25 \mathrm{~cm}^{2}\right.$ plastic culture flask) were treated with either D1 $(10 \mu \mathrm{M})$ or D6 $(5 \mu \mathrm{M}$ and $10 \mu \mathrm{M})$, collected, washed and processed using a human AnnexinV FITC kit (Bender MedSystems, Vienna, Austria), according to manufacturer's instructions and examined by two-color flow cytometry using a FACScan device $[18,14]$.

\section{Caspase $3 / 7$ activation}

Detection of caspase 3/7 cleavage activity was done using the Apo-ONER Homogeneous Caspase 3/7 Assay (Promega, Madison, WI, USA). GI-LI-N, SH-SY5Y, IMR-32, LB24 and M14 cell lines were seeded in 96-well plates $\left(10-20 \times 10^{3} /\right.$ well). Cells were then treated with D1 or D6 at a concentration of $10 \mu \mathrm{M}$ and $5 \mu \mathrm{M}$, respectively, for 24 hours. In some experiments, cells were treated for 1 hour with $100 \mu \mathrm{M}$ z-VAD-FMK caspase inhibitor before D1 and D6 administration. At the end of treatment, $100 \mu \mathrm{l}$ of the Apo-ONE Caspase 3-7 Reagent was added to each well, according to manufacturer's instructions. Cells were then incubated at room temperature in a plate shaker $(400 \mathrm{rpm})$ for 3 hours. Fluorescence was detected (485 $\mathrm{nm}$ excitation wavelength and 535 emission wavelength) using a fluorescence plate reader (SPECTRAFluor Plus, TECAN Austria, GmbH, Grodig/Salzburg, Austria). The amount of fluorescent product generated is proportional to the amount of caspase $3 / 7$ cleavage activity present in the sample.

\section{Mitochondrial membrane potential assay}

The mitochondrial permeability transition event was detected by MitoPT kit (Immunochemistry Technologies, LLC, Bloomington, MN, USA) according to the manufacturer's instructions. Briefly, IMR-32 and LB24 cell lines were plated in 6-well flat-bottomed plates $(0.7 \times$ $10^{6} /$ well and $0.4 \times 10^{6} /$ well, respectively). The cells were then treated with both D1 and D6 (2.5-10 $\mu \mathrm{M}$ and 5-10 $\mu \mathrm{M}$, respectively) for 18 hours, harvested, and processed as previously described $[18,19]$. The analysis was performed using a FACS Calibur (Beckton Dickinson, Franklin Lakes, NJ, USA). As the mitochondrial membrane potential collapsed (apoptosis), the amount of red fluorescence decreased.

\section{Western blot analysis}

Total cell lysates were prepared and analyzed by western blot analysis as described earlier $[18,19]$. Briefly, both $\mathrm{MM}$ and NB cell lines were untreated or treated with either D1 $(10 \mu \mathrm{M})$ or D6 $(5 \mu \mathrm{M})$ for 18,24 or 48 hours and then lysed with Cell Extraction Buffer (BioSource International, Camarillo, CA, USA) plus protease inhibitor cocktail (Sigma). To obtain subcellular fractions, the cells were processed with Qproteome Cell Compartment kit, according to the manufacturer's instructions (Qiagen, Crawley, UK), and resuspended with the above-mentioned lysis buffer. Protein lysates (50 $\mu \mathrm{g}$ per lane) were resolved on sodium dodecyl sulphate (SDS) 10 to $14 \%$ polyacrylamide gels and transferred to nitro-cellulose membranes; the membranes were then incubated with mouse monoclonal antibodies against procaspases 3, 9 (Cell Signaling Technology, Danvers, MA, USA) and NFkB (BD), or rabbit monoclonal antibody against PARP (Abcam, Cambridge, UK) or polyclonal antibody against cytochrome c (Cell Signaling Technology). Peroxidaseconjugated goat anti-mouse and anti-rabbit antibodies were used as secondary antibodies (Upstate, Lake Placid, NY, USA and Santa Cruz Biotechnology, Santa Cruz, CA, USA, respectively). Immune complexes were visualized with the use of an ECL Advance Western Blotting Detection kit (Amersham Bioscience), according to the manufacturer's instructions, and normalized to internal controls [a rabbit antibody against GAPDH (glyceraldehyde-3-phosphate dehydrogenase) (Sigma) and a mouse antibody against Lamin A/C (BD)].

\section{Animal models}

All animals were purchased from Harlan Laboratories (Harlan Italy, S.Pietro al Natisone, Italy) and housed under specific pathogen-free conditions. All experiments involving animals have been reviewed and approved by the licensing and ethical committee of the National Cancer Research Institute, Genoa, Italy and by Italian Ministry of Health. All the in vivo experiments were performed using 5-week-old female athymic (nude- $n u$ ), 5 to 8 mice per group and repeated at least twice with similar results.

For the melanoma animal model, $1.5 \times 10^{6} \mathrm{LB} 24$ cells were injected subcutaneously (s.c.) in the mid-dorsal of the mice, as previously reported [23]. Tumors were allowed to grow for 5 days, reaching a size of about 10 $\mathrm{mm}^{3}$, before intravenous (i.v.) treatment into tail vein.

For the neuroblastoma animal model, $1.5 \times 10^{6} \mathrm{GI}-\mathrm{LI}-\mathrm{N}$ cells were orthotopically injected in the capsule of the left adrenal gland of mice, as described previously $[24,19]$. In another set of experiments, mice were orthotopically injected with $1.5 \times 10^{6}$ luciferase-transfected GI-LI-N cells to monitor in vivo orthotopic tumor growth over time by bioluminescence imaging (BLI) [25].

\section{In vivo therapeutic studies}

In order to administer D1 and D6 by intravenous route (for a rapid and efficacious drug distribution), we have pre-dissolved curcuminoids in DMSO at $10 \mathrm{mM}$ and then diluted in a saline solution containing BSA, as previously suggested by others $(15,16)$ and by us (19) for waterinsoluble compounds. In the melanoma animal model, after tumor growing as above, mice were randomly assigned to three groups (8 mice/group) and treated with 
D1, D6 or with saline solution (control mice). Either D1 or D6 were i.v. injected at $17.5 \mathrm{mg} / \mathrm{Kg}$ twice a week for a total of 7 times. Moreover, at both 2 hours post the first injection and one day after the last one, four mice of each group of treatment were subjected to blood sample to test acute and chronic liver and renal toxicity using an automatic analyzer Kuadro Liquid Vet (BPC BioSed, Rome, Italy). Tumors were measured twice weekly with calipers and volume were calculated by the formula $4 / 3 \pi$ axbxc where $a, b$ and $c$ represented the values of all symmetric axes that constitute the ellipsoid tumor mass. At the end of the treatment, mice were killed by cervical dislocation after being anesthetized with xylazine (Xilor 2\%; Bio98 Srl, Milan, Italy), and their tumors were measured with caliper and then weighted.

For neuroblastoma animal model, tumors were allowed to grow for 14 days, and then mice, randomly assigned to three groups ( 8 or 5 mice/group), were treated with the same schedule used for the above melanoma animal model.

In all experiments, body weight and general physical status of the animals were recorded daily until they were judged to be in discomfort by animal caretakers. Specifically, once showing signs of poor health (i.e., abdominal dilatation, dehydration, paraplegia, severe weight loss) mice were euthanized, following anesthesia with xylazine and the day of euthanasia was recorded as the day of death.

\section{Statistical analysis}

All in vitro data derive from at least three independent experiments and results are expressed as mean values with $95 \%$ confidence intervals. The statistical significance of differential findings between experimental and control groups was determined by ANOVA with the Tukey's multiple comparison test in Graph-Pad Prism 3.0 software (Graph-Pad Software, Inc, San Diego, CA, USA). These findings were considered significant if two-tailed $P$ values were $<0.05$. Survival curves have been constructed with the Kaplan Meier method. All the in vivo experiments were performed at least twice with similar results. A $P$ value less than 0.05 has been considered as statistically significant by the use of the Peto's log-rank test in GraphPad Prism 3.0 software.

\section{Results}

Effects of D1 and D6 on proliferation, clonal growth and viability of melanoma and neuroblastoma cell lines

Cell proliferation assays were performed to assess the cytotoxic activity of the novel biphenyl, curcumin-related compound D6 (see Figure 1) in comparison with that of curcumin D1. Figure 2 shows the dose-dependent cell growth inhibition of $6 \mathrm{NB}$ cell lines treated with either D1 (panel A) or D6 (panel B), clearly evidencing the stronger efficacy of D6 at very low doses (1-2.5 $\mu \mathrm{M})$ after three days of treatment. MM cells growth inhibition gave similar results and a summary of all the $\mathrm{IC}_{50}$ values obtained at 72 hours for MM and NB cell lines for both compounds is reported in figure 2, panel $\mathrm{C}$. Considering the $\mathrm{IC}_{50}$ mean values \pm s.d. obtained for all $\mathrm{NB}$ and $\mathrm{MM}$ cell lines tested we can note that D6 is about 5-10 fold more efficient than D1 in both cases.

To assess the impact of D6 exposure time on cell proliferation, washout experiments were performed. These experiments simulated the in vivo activity of D6, testing the minimum time of response of the tumor cells to the drug. D6 action was very powerful and rapid in arresting NB and MM cells growth: a single 6 hours treatment was sufficient to inhibit tumor cells proliferation up to 75$90 \%$, having a small effect (10-20\%) on BJ normal fibroblasts (Figure 2, panels D, E). Moreover cell proliferation capability was not restored when cells were grown in the absence of the drug up to 72 hours, showing that the antiproliferative effect of D6 was irreversible. Washout experiments performed using D1 instead, did not show any appreciable activity on cell proliferation for both type of tumor cells (Additional file 1 Figure S1).

To measure long-term effects of D1 and D6 on permanent cell growth arrest and cell death we performed clonogenic survival assays. Clonal growth of both LB24 melanoma cells and GI-LI-N neuroblastoma cells was inhibited by D6 in a dose dependent manner as shown in figure 3. Conversely, D1 was not able to abolish colony formation under the same conditions, but partly inhibited clonogenic growth only at the highest concentration used $(20 \mu \mathrm{M})$.

\section{D1 and D6 induce apoptosis in both melanoma and neuroblastoma cells}

To determine whether the observed D1- and D6-induced reduction in viability of both melanoma and neuroblastoma cell lines occurred via activation of apoptosis, we used TUNEL staining to highlight DNA fragmentation and Annexin- $\mathrm{V}$ assay, in which Annexin- $\mathrm{V}$ binds to externalized phosphatidylserine on the surface of apoptotic cells. TUNEL assay in figure 4, panel A shows a higher proportion of apoptotic melanoma cells in the D6 treated sample compared to the D1 treated one, while human BJ fibroblast cells appear not to be affected by these treatments. Furthermore, when LB24 melanoma cells were exposed for 24 and 48 hours to 5 and $10 \mu \mathrm{M}$ of both D1 and D6, a significant, time- and dose-dependent, increase in the percentage of Annexin-V-positive cells was observed, particularly following D6 treatment (Figure 4, panel B). Similar results were obtained with GI-LI-N neuroblastoma cells (Figure 4, panel C). (*, $P<0.05$; ${ }^{* *}, P<$ $0.01 ;{ }^{* * * * *}, P<0.001$ vs untreated cells). 
(A)



(B)

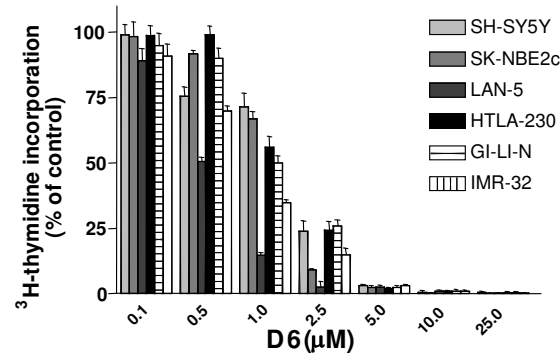

(C)

\begin{tabular}{|c|c|c|c|}
\hline \multicolumn{4}{|c|}{$\mathrm{IC}_{50}(\mu \mathrm{M})$ at 72 hours } \\
\hline \multicolumn{3}{|c|}{$\mathrm{MM}$} & \multicolumn{2}{c|}{$\mathrm{NB}$} \\
\hline $\mathrm{D} 1$ & $\mathrm{D} 6$ & $\mathrm{D} 1$ & $\mathrm{D} 6$ \\
\hline $10,2 \pm 1,9$ & $1,8 \pm 0,9$ & $7,7 \pm 1,1$ & $1,4 \pm 0,3$ \\
\hline
\end{tabular}

(D)



(E)

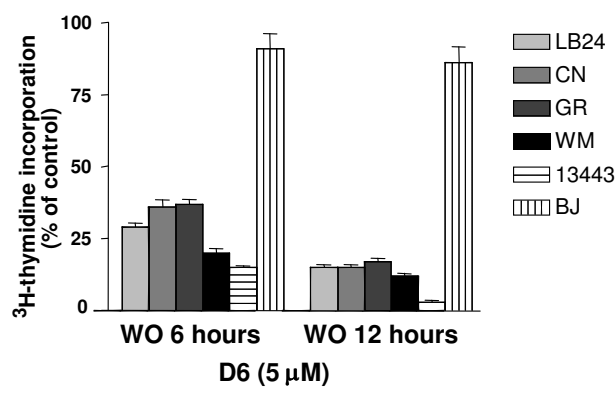

Figure 2 Effects of D1 and D6 on the growth of human neuroblastoma and melanoma cell lines. (A), (B): Six NB cell lines were cultured in the presence of various concentrations (0-25 $\mu \mathrm{M})$ of D1 (A) and D6 (B) or 0.1\% DMSO (control cells) for 72 hours. Cell proliferation was measured by ${ }^{3 \mathrm{H}}$ thymidine incorporation. Results, derived from three different experiments, are expressed as mean percentage of $3 \mathrm{H}$-thymidine incorporation from quadruplicate wells as compared to that of control cells. Error bars represent $95 \%$ confidence intervals. $(\mathbf{C}) I_{50}$ values obtained on the six NB cell lines and the six MM cell lines reported in the M\&M section. (D) and (E): drug washout assays to assess the impact of D6 time exposure on cell proliferation in NB cells (D), MM cells and BJ fibroblasts (E). Cells were incubated with D6 for the indicated times and concentration and then washed and cultured in drug-free medium up to 72 hours. Cell proliferation was assessed by ${ }^{3} \mathrm{H}$-thymidine incorporation. Results are expressed as described above.

Activation of aspartate specific cysteine proteases or caspases may be involved in induction of apoptosis [26]. Caspase 3/7 assays showed that both D1 and D6 (at 10 $\mu \mathrm{M}$ and $5 \mu \mathrm{M}$, respectively) significantly induced the cleavage of caspases 3 and 7 in GI-LI-N neuroblastoma cells and LB24 melanoma cells (Figure 5, panels A and B, respectively). In both cases D1 and D6 vs control showed a very significative value ${ }^{* * * *}, P<0.001$ and the effect of D6 was stronger when compared to D1 for both cell lines. A pre-incubation with the pan-caspase inhibitor z-VADFMK completely abolished the D1 and D6-induced caspases 3 and 7 cleavage activity, meaning that caspases are involved in this cell death. Since activation of caspases 3 and 7 has been reported to also belong to the intrinsic apoptotic signaling pathway $[27,28]$, we decided to investigate mitochondria-related events, mitochondrial membrane damage and release of the cytochrome $c$ into the cytosol, which is putatively involved in the curcuminoidstriggered cell death. The percentage of both IMR-32 and LB24 cells with polarized mitochondria decreased after 18 hours treatment with the above mentioned doses of D1 and D6: this reduction was statistically significant and highlighted, also in this context, the major sensitivity of neuroblastoma cells to D6 (Figure 5, panel C: IMR-32: D1 vs control: *, $P<0.05$ and D6 vs control: ***, $P<0.001$; LB24: both D1 and D6 vs control: *, $P<0.05)$. The resulting release of cytochrome $c$ from mitochondria appeared more consistent after D6 treatment in both IMR-32 and LB24 cell lines (Figure 5, panel D). Consistently, this event led to caspase 9 activation in both NB and MM cells, indicating that, together with the disruption of mitochondrial membrane potential, the intrinsic apoptotic pathway was involved in this gene activation cascade. Moreover, the level of pro-caspase 3 was also decreased in response to 


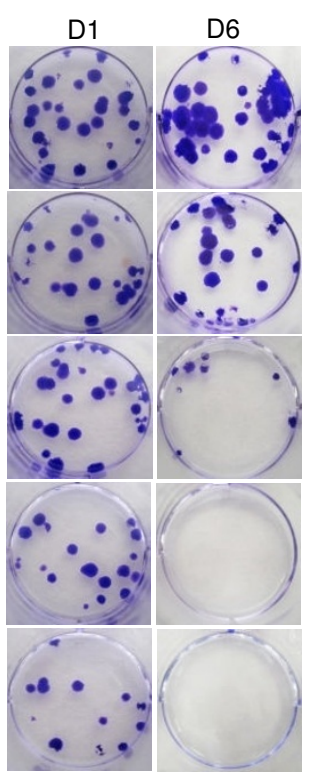

LB24 cells $\mu \mathrm{M}$

$(-)$

(2.5)

(5)

(10)

(20)

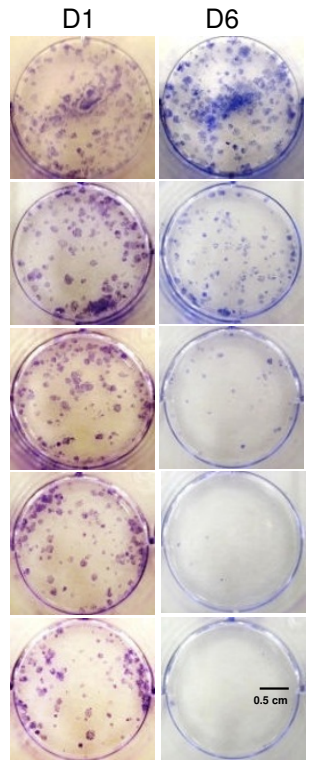

GI-LI-N cells
Figure 3 Effects of D1 and D6 on the clonogenic growth of melanoma (LB24) and neuroblastoma (GI-LI-N) cell lines. Cells have been suspended in drug-containing medium at different concentrations $(0-20 \mu \mathrm{M})$ of D 1 and D6 for 4 hours and then washed, seeded with drug-free medium in a 12 well-plate and let grow up to 14 days. Cell colonies were stained with crystal violet, counted and photographed as described in $M \& M$.

D6 treatment and this event culminated in the cleavage of poly(ADP)ribose polymerase (PARP), confirming the occurring of programmed cell death (Figure 5, panel E).

\section{In vivo anti-tumor activity of D1 and D6 against human neuroectoderma-derived xenografts}

We used two previously described animal models, a subcute tumor model for melanoma [23] and an orthotopic xenograft model for neuroblastoma [19] to evaluate whether D1 and D6 would inhibit neuroectodermaderived cell growth in vivo.

In cancer related research, curcuminoids have been used in cell culture systems, animal models and clinical trials $[9,29,30]$. Unfortunately, the study of curcuminoids is severely limited by their extremely low bioavailability following oral administration. Moreover, only predissolving curcuminoids in DMSO render them in a physical form, that is proper for solubilization in aqueous media containing serum or preferentially BSA [16]. Then, in a set of preliminary experiments, we have injected D1 and D6 in the tail vein and we have been able to obtain good animal responses to a restrict range of administered doses $(15-25 \mathrm{mg} / \mathrm{Kg})$, in terms of good health (i.e., no abdominal dilatation, dehydration, paraplegia, severe weight loss), together with slightly variations in both liver
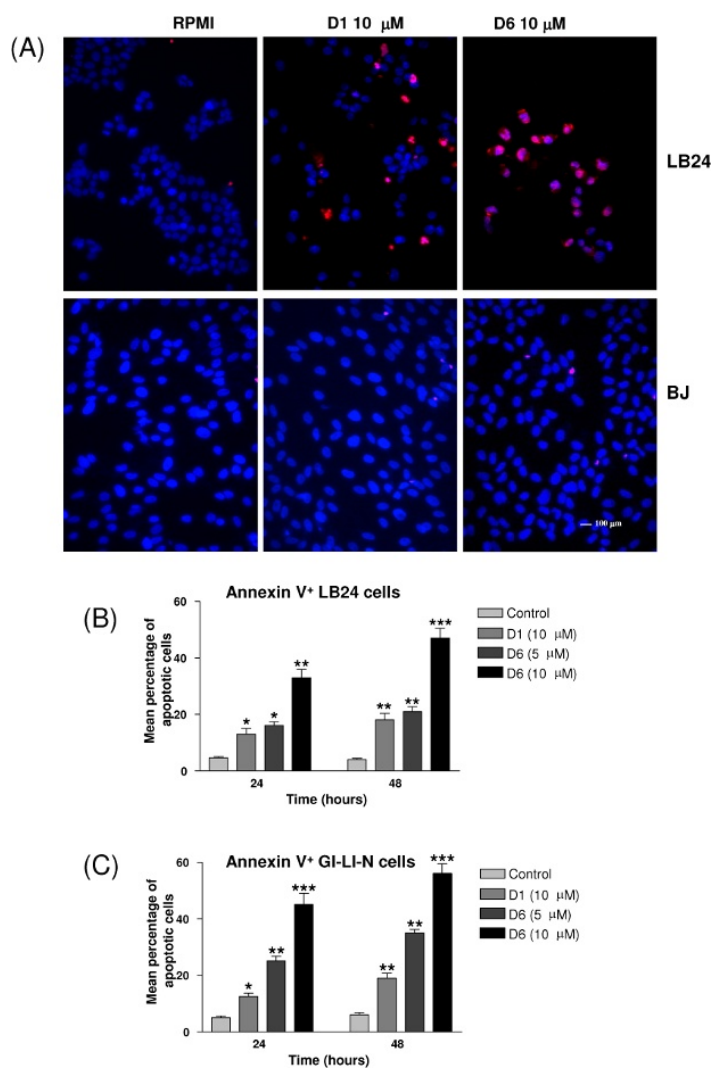

Figure 4 Effects of D1 and D6 on apoptosis in melanoma and neuroblastoma cells. (A) Melanoma cells (LB24) and normal fibroblasts (BJ) were incubated with solvent (control), or with $10 \mu \mathrm{MD} 1$ and D6 for 24 hours, then stained by TUNEL assay. Apoptotic cells are visualized by red staining. Cell nuclei (blue) were stained with DAPI (bar, $100 \mu \mathrm{m})$. (B) Melanoma cells (LB24) and (C) Neuroblastoma cells (GI-LI-N) were incubated with $10 \mu \mathrm{MD} 1$ and with 5 and $10 \mu \mathrm{MD} 6$ for 24 and 48 hours. Apoptosis induction was determined as the percentage of Annexin- $V$ positive cells. Columns: means; bars: SD. ${ }^{*}, P<0.05 ;{ }^{* *}, P<0.01$; ${ }^{* *}, P<$ 0.001 vs control levels.

and renal enzymatic values, only at the higher doses throughout the experiments. Therefore, after both subcutaneous injection of LB24 melanoma cells and orthotopic implantation of GI-LI-N neuroblastoma cells, we treated mice with $17,5 \mathrm{mg} / \mathrm{Kg}$ of D1 and D6 by i.v. injection twice a week, for 7 times.

In melanoma-bearing mice (Figure 6, panel A), both D1 and D6 induced a significant inhibition of tumor growth when compared to that of untreated mice. Noteworthy, the D6 inhibitory effect was already evident at early days of treatment, and it was more statistically efficacious than D1 (D6 vs D1, $P<0.01$ ). The pronounced delay in tumor growth, especially by D6, was translated into tumor weight values, which have been obtained at the end of the treatment (Figure 6, panel B: both D1 and D6 vs control, ***, $P<0.001$; D6 vs D1, *, $P<0.05)$. 
$(A)$

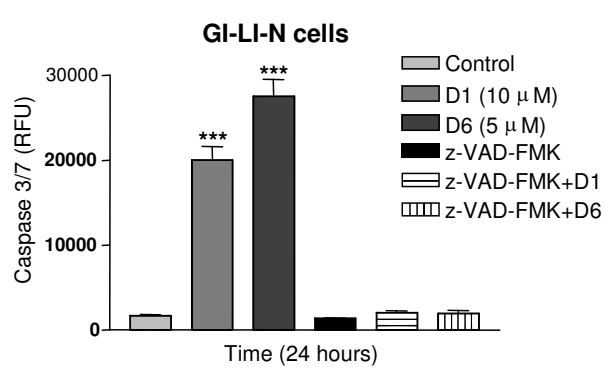

$(\mathrm{C})$

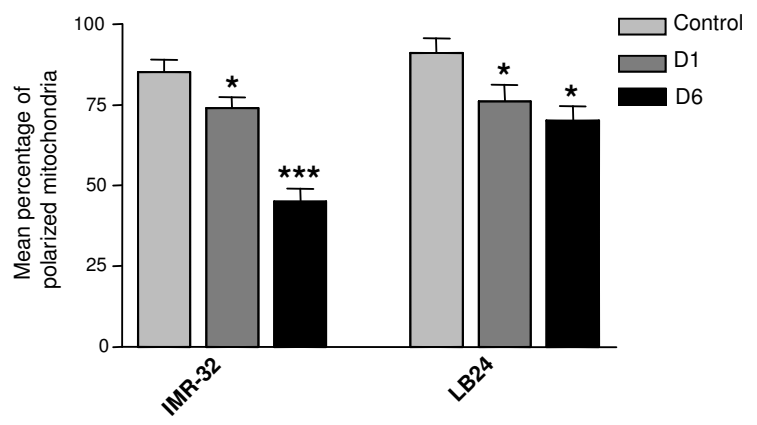

(B)



(D)

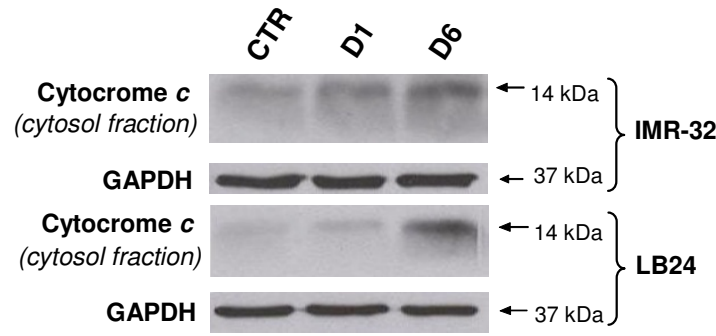

(E)



Figure 5 D6 and D1 triggered-apoptosis is caspase-dependent and involves the apoptotic intrinsic pathway. (A) and (B): Caspase 3/7 activation was assessed on GI-LI-N cells (A) and LB24 cells (B), untreated (control), or treated with D1 (10 $\mu \mathrm{M})$ and D6 (5 $\mu \mathrm{M})$ for 24 hours. Cells received an 1 hour pre-treatment with a pan-caspases inhibitor (z-VAD-FMK). RFU: Relative Fluorescence Unit. ${ }^{* *}, P<0.001$ vs control. (C) To assess the effects of drugs on mitochondrial membrane permeability, neuroblastoma IMR-32 and melanoma LB24 cells were untreated (control) or treated with D1 and D6, as above, for 18 hours, harvested, and analyzed for changes in mitochondrial membrane potential. Results are expressed as the mean percentage of cells with polarized mitochondria from four independent experiments; error bars, $95 \%$ Cls. ${ }^{*}, \mathrm{P}<0.05$; **, $\mathrm{P}<0.001$ vs control. (D) IMR-32 and LB24 cells were treated for 24 hours as above and fractionated cellular lysates were analyzed by western blot with a specific primary antibody for cytochrome c. GAPDH was used as loading control. (E) SH-SY5Y, HTLA-230, GI-LI-N neuroblastoma cell lines and LB24, M14, WM melanoma cell lines were treated as in panel $D$ for 48 hours and total cellular lysates were analyzed by western blot with specific primary antibodies for procaspase 9 , procaspase 3 and poly(ADP)ribose polymerase (PARP). As for (D), blots are representative of three independent experiments and data were normalized against GAPDH. 
(A)
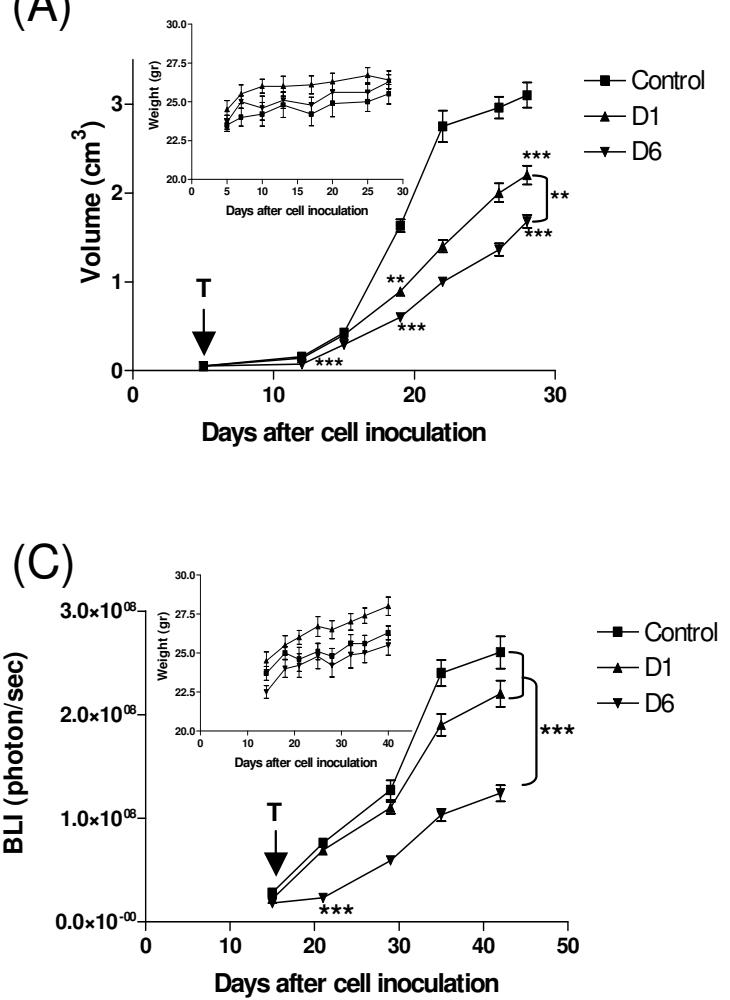

(B)



(D)

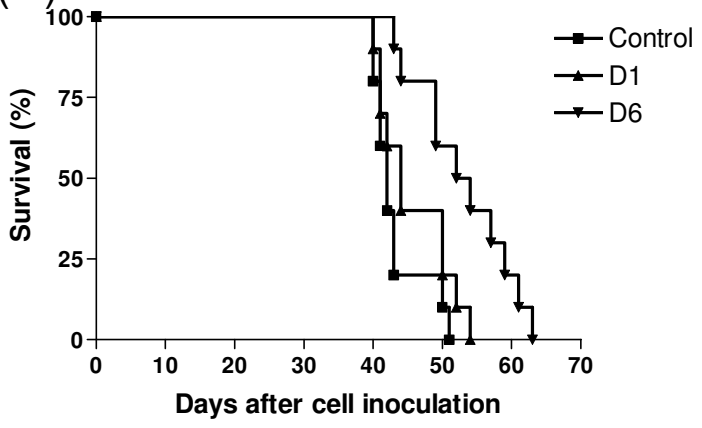

Figure $\mathbf{6}$ In vivo anti-tumor activity of D1 and D6. (A), (B): in the melanoma animal model, nude mice ( $\mathrm{n}=8 \mathrm{mice} / \mathrm{group}$ ) received i.v. $17.5 \mathrm{mg} / \mathrm{kg}$ of D1 and D6 or saline solution (control mice) on day 5 after s.c. injection of $1.5 \times 10^{6}$ LB24 cells, twice a week, for 7 times. (A) Tumor volumes were measured at different times points after cell inoculation. $P$ values were calculated using Peto's log-rank test $\left({ }^{* *}, P<0.01 ;{ }^{* *}, P<0.001\right)$. Inset: absolute mean body weight, in grams, after the beginning of the treatment. (B) Two days after the end of the treatment, mice were sacrificed and tumors were excised and weighted. Bars depict the mean values and error bars represent $95 \%$ confidence intervals. $P$ values were calculated using ANOVA with Tukey's multiple comparison test $\left({ }^{*}, P<0.05 ;{ }^{* * *}, P<0.001\right)$. (C): Nude mice were orthotopically injected with $1.5 \times 10^{6}$ luciferase-transfected GI-LI-N neuroblastoma cells and tumors were allowed to grow for 14 days, then mice, randomly assigned to three groups (5 mice/group), were treated with the same schedule used for the above melanoma animal model. Orthotopic tumor growth was monitored over time by bioluminescence imaging (BLI). P values were calculated using Peto's log-rank test (***, $P<0.001)$. Inset: absolute mean body weight, in grams, after the beginning of the treatment. (D) Therapeutic effects on survival were evaluated on nude mice ( $\mathrm{n}=8$ mice/group) orthotopically injected with $1.5 \times 10^{6} \mathrm{GI}-\mathrm{LI}-\mathrm{N}$ cells in the left adrenal gland and treated as above. Survival of mice was monitored daily. $P=0.0007$ for D6 over control and $P=0.0169$ for D6 over D1.

Even in the neuroblastoma animal model, D6 induced a statistically significant more pronounced tumor growth reduction than D1 evaluated by means of BLI (Figure 6, panel C: D6 vs both D1 and control, $P<0.001)$. More importantly, the survival rate was significantly increased only by the D6 treatment (Figure 6, panel D: D6 vs control, $P=0.0007$; D6 vs D1, $P=0.0169$ ).

In the two experimental animal models, the mean body weight of both D1 and D6-treated mice was not significantly lower than that of saline-injected (control) mice, indicating that the molecules had minimal side effects (Insets, Figure 6, panels A and C). Besides, this good systemic tolerability was also confirmed by the trend of both liver and renal enzymatic values throughout the experiments (Additional file 2 Table S1).

\section{Discussion}

Despite the current advances in anticancer therapies, the clinical prognosis of both malignant melanoma and aggressive neuroblastoma remain fatal. For this reason search of effective novel drugs, with low systemic toxicity, is a main field in oncology research.

Curcumin, which is a natural derived compound, considered pharmacologically safe even at high doses [31], has been shown to prevent tumor formation and progression in many cancer types as well as to exert growth inhibitory effects on several neoplastic cells [10]. In this 
study, we demonstrated that a newly-synthesized curcumin-related biphenyl compound, the $\alpha, \beta$-unsaturated ketone D6, acts as a very promising anticancer molecule, being more effective than curcumin in inhibiting neuroectodermal derived cancer cells growth by inducing apoptosis. In particular, D6 caused proliferation arrest in cultured NB and MM cells at low concentrations (1-5 $\mu \mathrm{M})$, whereas curcumin reached the same effects at concentrations 5-10 fold higher. Moreover D6 treatments had no effect on normal fibroblasts at the same concentrations suggesting that this compound shows preferential cytotoxic activity on cancer cells. In vitro response to a given drug could be influenced by cell culture conditions: usually, cells grown in monolayer are more sensitive to cytotoxic agents than cells grown in colonies because of the larger surface they expose to the drug, compared to the limited drug penetration in the colonies [32]. Moreover in vivo growth rate of solid tumors is typically lower than that of in vitro monolayer cultures. Our results showed that D6 is similarly efficient in suppressing in vitro proliferation of $\mathrm{NB}$ and $\mathrm{MM}$ cells in both monolayer and colony cell culture conditions. This finding suggests that D6 could probably exploit its in vivo anticancer activity without being influenced by the low fraction of proliferating cells in solid tumors, which is a limit of many of the conventional cell cycle-dependent chemotherapeutic agents [33].

Several studies indicated curcumin as a proapoptotic agent against different types of cancer cells (reviewed in [9]); therefore, we investigated whether D6-driven proliferation arrest was due to induction of apoptosis. In our experiments, both NB and MM cells presented apoptosis following D6 treatments. Moreover, a more consistent portion of apoptotic MM cells was observed in cells treated with D6 compared to those treated with curcumin. Interestingly, no evidence of apoptosis was observed in normal human BJ fibroblasts grown in the same conditions, again suggesting the preferential antiproliferative activity of D6 on cancer cells.

Induction of apoptosis may also involve activation of aspartate specific cysteine proteases or caspases. Our results show that activation of both caspase 3 and caspase 7 occurred after treatment of NB and MM cells with D6, again being more efficient than the treatment with D1. One of the hallmark of caspase activation is polyadenosine-5'-diphosphate-ribose-polymerase (PARP) cleavage, where the native $116 \mathrm{kD}$ polypeptide is cleaved to a smaller $85 \mathrm{kD}$ fragment. Usually, PARP inactivation is dependent on caspase 3 , which has a central role in the apoptosis process collecting signals coming from both intrinsic and extrinsic pathways. Induction of apoptosis by curcumin has been reported to occur through both mitochondrial intrinsic pathway [34] and death receptor mediated extrinsic pathway [13]. Cleavage of procaspase
9 in the D6 treated cells suggested the involvement of mitochondrial pathway in the mechanism of action of this compound; indeed, this hypothesis was validated by the observation of mitochondrial membrane depolarization. Noteworthy, all the apoptosis hallmarks were found significantly higher in D6-treated than curcumin/D1treated cells, strongly suggesting that D6 may act as a more effective proapoptotic agent.

Considering our in vivo data, both NB and MM xenografts showed a good response to the D6 treatments: tumor mass growth was significantly reduced compared to control mice, especially after the D6 administration. Importantly, the survival time increased in a statistically significant way among D6 treated mice, while no evident side effects were observed. On this regard, mean body weight of treated mice was not affected by either D1 or D6 administration and both liver and renal functionality showed to be normal (see Additional file 2 Table S1). These findings confirmed that this class of compounds, such as curcumin, has good tolerability and an interesting anticancer proapoptotic activity.

Curcumin has been reported to act as anticancer agent by suppressing NFkB signaling (reviewed in [35] and [9]). Constitutively active form of NFkB has been reported in several human cancers [36] and activated NFkB suppresses apoptosis in a wide variety of cancer cells [37]. When we investigated the possible involvement of NFkB signaling suppression in D6 antiproliferative activity we found out that our cell lines did not show constitutive activation of this transcription factor so that probably this pathway is not involved in the transformation processes of these cells (see Additional file 3 Figure S2). The curcumin and D6 antiproliferative and proapoptotic action on our MM and NB cells must be therefore due to different mechanisms. Nevertheless, when NFkB activation and nuclear translocation was induced in NB cells by TNF $\alpha$ or doxorubicin pretreatments, D1 and, even better, D6 administration to the cells consistently inhibited NFkB activation, indicating the capability of these compounds to interfere with such molecular activation of transcription pathway. The last evidence points out the potentiality of D6 to be used in combination with chemotherapeutic agents which stimulate the activation of gene transcription through NFkB pathway, such as doxorubi$\operatorname{cin}[38]$.

\section{Conclusions}

In summary, we have demonstrated that hydroxylated biphenyls structurally related to curcumin are a class of molecules worth to be studied for its promising antiproliferative and proapoptotic features. Moreover, although a large selection of curcumin analogues have been published and tested as antitumoral agents [39], no examples of hydroxylated biphenyl curcumin-related have been 
published before. Specifically, D6 activity seems to be effective, rapid, and selective against both NB and MM cells, by causing apoptosis in vitro and reduction of tumor mass growth in mice models in vivo. Such an antiproliferative activity seems to be achieved using lower concentrations than curcumin. As a consequence, D6 could be considered a good candidate to develop new therapeutic strategies against tumors with neuroectodermal origin.

\section{Additional material}

Additional file 1 Figure $\mathrm{S} 1$. Effects of $\mathrm{D} 1$ on melanoma and neuroblastoma cell proliferation analyzed with drug washout experiments

Additional file $\mathbf{2}$ Table S1. Liver and renal toxicity values during the invivo therapeutic studies

Additional file $\mathbf{3}$ Figure $\mathbf{S 2}$. Effects of D1 and D6 on NFkB expression in neuroblastoma cell line (figure, legend and methods)

\section{Competing interests}

The authors declare that they have no competing interests.

\section{Authors' contributions}

MPisano carried out melanoma cell cultures, cell proliferation assays, clonogenic cell survival assays, western blot analysis, TUNEL assays and drafted the manuscript. GPagnan carried out neuroblastoma cell cultures, cell proliferation assays, phospatidylserine detection, caspase 3/7 activation assays, mitochondrial membrane potential assay, western blot analysis, in vivo therapeutic studies and drafted the manuscript. MAD, DF and GD performed the chemical synthesis and the resolution of the curcumin-related biphenyl compound D6. SC and IS participated to melanoma cell cultures, cell proliferation assays, clonogenic cell survival assays, western blot analysis and TUNEL assays. IC participated to neuroblastoma cell cultures, cell proliferation assays, phosphatidylserine detection, caspase 3/7 activation assays, mitochondrial membrane potential assay, western blot analysis, in vivo therapeutic studies. LE and $\mathrm{MC}$ carried out animal models establishments and animals care. FP participated to animal models establishment and in vivo therapeutic studies. GPalmieri contributed to the final drafting and critical revision of the manuscript. MPonzoni performed statistical analysis, CR carried out western blot analysis and together they conceived of the study, participated in its design and coordination and carried out the final drafting of the manuscript. All authors read and approved the final manuscript.

\section{Acknowledgements}

We thank Fondazione Italiana per la Lotta al Neuroblastoma, AIRC, Italian Ministry of Health and Sardinian Autonomous Region for financial support; D. Marimpietri, C. Brignole, G. Taverniti for expert technical assistance and C. Bernardini for editing.

\section{Author Details}

'Istituto di Chimica Biomolecolare, CNR, Sassari, Italy, 2Laboratory of Oncology, "G. Gaslini" Children's Hospital, Genoa, Italy and ${ }^{3}$ Animal Research Facility, Istituto Tumori, Genoa, Italy

Received: 4 February 2010 Accepted: 3 June 2010

Published: 3 June 2010

\section{References}

1. de Vries E, Coebergh JW: Melanoma incidence has risen in Europe. BMJ 2005, 331:698.

2. Lipsker D, Engel F, Cribier B, Velten M, Hedelin G: Trends in melanoma epidemiology suggest three different types of melanoma. $\mathrm{Br} J$ Dermatol 2007, 157:338-343

3. Cummins DL, Cummins JM, Pantle H, Silverman MA, Leonard AL, Chanmugam A: Cutaneous malignant melanoma. Mayo Clin Proc 2006, 81:500-507.
4. Wagner LM, Danks MK: New therapeutic targets for the treatment of high-risk neuroblastoma. J Cell Biochem 2009, 107:46-57.

5. Muller S, Matthay KK: Neuroblastoma: biology and staging. Current Oncology Reports 2009, 11:431-438.

6. Oberthuer A, Theissen J, Westermann F, Hero B, Fisher M: Molecular characterization and classification of neuroblastoma. Future Oncology 2009, 5:625-639.

7. Shishodia S, Sethi G, Aggarwal BB: Curcumin: getting back to the roots. Ann NY Acad Sci 2005, 1056:206-217.

8. Sharma RA, Gescher AJ, Steward WP: Curcumin: The story so far. Eur J Cancer 2005, 41:1955-1968.

9. Shishodia S, Chaturvedi MM, Aggarwal BB: Role of curcumin in cancer therapy. Curr Probl Cancer 2007, 31:243-305.

10. Anand P, Sundaram C, Jhurani S, Kunnumakkara A, Aggarwal BB: Curcumin and cancer: An "old-age" disease with an "alge-old" solution. Cancer Lett 2008, 267:133-64

11. Aggarwal BB, Kumar A, Bharti AC: Anticancer potential of curcumin: preclinical and clinical studies. Anticancer Res 2003, 23:363-98.

12. Marìn YE, Wall BA, Wang S, Namkoong J, Martino JJ, Suh J, Lee HJ, Rabson $A B$, Yang CS, Chen S, Ryu JH: Curcumin downregulates the constitutive activity of NF-kB and induces apoptosis in novel mouse melanoma cells. Melanoma Res 2007, 17:274-283.

13. Bush JA, Cheung KJ Jr, Li G: Curcumin induces apoptosis in human melanoma cells through a Fas receptor/caspase-8 pathway independent of p53. Exp Cell Res 2001, 271:305-14.

14. Pisano M, Pagnan G, Loi M, Mura ME, Tilocca MG, Palmieri G, Fabbri D, Dettori MA, Delogu G, Ponzoni M, Rozzo C: Antiproliferative and proapoptotic activity of eugenol-related biphenyls on malignant melanoma cells. Mol Cancer 2007, 6:8

15. Formelli $F$, Cleris $L$ : Therapeutic effects of the combination of fenretinide and all-trans-retinoic acid and of the two retinoids with cisplatin in a human ovarian carcinoma xenograft and in a cisplatinresistant subline. Eur J Cancer 2000, 36:2411-9.

16. Quitschke WW: Differential solubility of curcuminoids in serum and albumin solutions: implications for analytical and therapeutic applications. BMC Biotechnol 2008, 8:84

17. Delomenede $M$, Bedos-Belval F, Duran $H$, Vindis $C$, Balta $M$, Ne' greSalvayre A: Development of Novel Antiatherogenic Biaryls: Design, Synthesis, and Reactivity. J Med Chem 2008, 51:3171-3181.

18. Brignole C, Marimpietri D, Pastorino F, Nico B, Di Paolo D, Cioni M, Piccardi F, Cilli M, Pezzolo A, Corrias MV, Pistoia V, Ribatti D, Pagnan G, Ponzoni M: Effect of bortezomib on human neuroblastoma cell growth, apoptosis, and angiogenesis. J Natl Cancer Inst 2006, 98:1142-57.

19. Pagnan G, Di Paolo D, Carosio R, Pastorino F, Marimpietri D, Brignole $C$ Pezzolo A, Loi M, Galietta L, Piccardi F, Cilli M, Nico B, Ribatti D, Pistoia V, Ponzoni M: The combined therapeutic effects of bortezomib and fenretinide on neuroblastoma cells involve endoplasmic reticulum stress response. Clin Cancer Res 2009, 15:1 199-209.

20. Kueng W, Silber E, Eppenberger U: Quantification of cells cultured on 96well plates. Anal Biochem 1989, 182:16-19.

21. Marimpietri $D$, Nico B, Vacca A, Mangieri D, Catarsi P, Ponzoni M Synergistic inhibition of human neuroblastoma-related angiogenesis by vinblastine and rapamycin. Oncogene 2005, 24:6785-6795.

22. Keshelava N, Tsao-Wei $D$, Reynolds CP: Pyrazoloacridine is active in multidrugresistant neuroblastoma cell lines with nonfunctional p53. Clin Cancer Res 2003, 9:3492-3502.

23. Pastorino F, Mumbengegwi DR, Ribatti D, Ponzoni M, Allen TM: Increase of therapeutic effects by treating melanoma with targeted combinations of c-myc antisense and doxorubicin. $J$ Control Release 2008, 126:85-94.

24. Pastorino F, Di Paolo D, Piccardi F, Nico B, Ribatti D, Daga A, Baio G, Neumaier CE, Brignole C, Loi M, Marimpietri D, Pagnan G, Cilli M, Lepekhin EA, Garde SV, Longhi R, Corti A, Allen TM, Wu JJ, Ponzoni M: Enhanced antitumor efficacy of clinical-grade vasculature-targeted liposomal doxorubicin. Clin Cancer Res 2008, 14:7320-9.

25. Pastorino F, Marimpietri D, Brignole C, Di Paolo D, Pagnan G, Daga A, Piccardi F, Cilli M, Allen TM, Ponzoni M: Ligand targeted liposomal therapies of neuroblastoma. Curr Med Chem 2007, 14:3070-8.

26. Thornberry NA, Lazebnik Y: Caspases: enemies within. Science 1998, 281:1312-6

27. Green DR, Reed JC: Mitochondria and apoptosis. Science 1998, 281:1309-12. 
28. Varfolomeev E, Alicke B, Elliott JM, Zobel K, West K, Wong H, Scheer JM, Ashkenazi A, Gould SE, Fairbrother WJ, Vucic D: X chromosome-linked inhibitor of apoptosis regulates cell death induction by proapoptotic receptor agonists. J Biol Chem 2009, 284:34553-60.

29. Karunagaran D, Rashmi R, Kumar TR: Induction of apoptosis by curcumin and its implications for cancer therapy. Curr Cancer Drug Targets 2005, 5:117-29.

30. Sharma RA, McLelland HR, Hill KA, Ireson CR, Euden SA, Manson MM, Pirmohamed M, Marnett LJ, Gescher AJ, Steward WP: Pharmacodynamic and pharmacokinetic study of oral Curcuma extract in patients with colorectal cancer. Clin Cancer Res 2001, 7:1894-900.

31. Ammon HP, Wahl MA: Pharmacology of Curcuma longa. Planta Med 1991, 57:1-7.

32. Brown JM, Attardi LD: The role of apoptosis in cancer development and treatment response. Nat Rev Cancer 2005, 5:231-7.

33. Boyer MJ, Tannock IF: Cellular and molecular basis of chemotherapy. In The Basic Science of Oncology Edited by: Tannock IF, Hill RP. New York: McGraw-Hill; 1998:350-369.

34. Woo JH, Kim YH, Choi YJ, Kim DG, Lee KS, Bae JH, Min DS, Chang JS, Jeong YJ, Lee YH, Park JW, Kwon TK: Molecular mechanisms of curcumininduced cytotoxicity: induction of apoptosis through generation of reactive oxygen species, down-regulation of $\mathrm{BCl}-\mathrm{XL}$ and IAP, the release of cytochrome $\mathrm{c}$ and inhibition of Akt. Carcinogenesis 2003, 24:1199-208.

35. Chih-Li Lin, Jen-Kun Lin: Curcumin: a Potential Cancer Chemopreventive Agent through Suppressing NF-kB Signaling. J Cancer Mol 2008, 4:11-16.

36. Rayet $B$, Gelinas C: Aberrant rel/nfkb genes and activity in human cancers. Oncogene 1999, 18:6938-6947.

37. Barkett M, Gilmore TD: Control of apoptosis by Rel/NF-kB transcription factors. Oncogene 1999, 18:6910-6924.

38. Aggarwal BB, Vijayalekshmi RV, Sung B: Targeting inflammatory pathways for prevention and therapy of cancer: short-term friend, long-term foe. Clin Cancer Res 2009, 15:425-430.

39. Liang G, Shao L, Wang Y, Zhao C, Chu Y, Xiao J, Zhao Y, Li Xb, Yang S: Exploration and synthesis of curcumin analogues with improved structural stability both in vitro and in vivo as cytotoxic agents. Bioorg Med Chem 2009, 17:2623-2631.

doi: 10.1186/1476-4598-9-137

Cite this article as: Pisano et al., Enhanced anti-tumor activity of a new curcumin-related compound against melanoma and neuroblastoma cells Molecular Cancer 2010, 9:137

\section{Submit your next manuscript to BioMed Central} and take full advantage of:

- Convenient online submission

- Thorough peer review

- No space constraints or color figure charges

- Immediate publication on acceptance

- Inclusion in PubMed, CAS, Scopus and Google Scholar

- Research which is freely available for redistribution

Submit your manuscript at www.biomedcentral.com/submit
C Biomed Central 